\title{
A Study of SiR/EPDM Mixtures for Outdoor Insulators
}

\author{
A. Sykaras \\ Democritus University of \\ Thrace, Department of \\ Electrical and Computer \\ Engineering, Xanthi, \\ Greece
}

\author{
V. Rajini \\ SSN College of \\ Engineering, Department \\ of Electrical and \\ Electronics Engineering, \\ Chennai, India
}

\author{
M. G. Danikas \\ Democritus University of \\ Thrace, Department of \\ Electrical and Computer \\ Engineering, Xanthi, \\ Greece
}

\author{
R. Sarathi \\ Indian Institute of \\ Technology Madras, \\ Department of Electrical \\ Engineering, Chennai, \\ Tamil Nadu, India
}

\begin{abstract}
This paper deals with the flashover voltages on samples of silicone rubber/ethylene propylene diene monomer (SiR/EPDM) mixtures under the influence of a uniform electric field. Five different mixtures of SiR/EPDM were investigated. Various SiR/EPDM mixtures (100\% EPDM, $10 \% \mathrm{SiR}+\mathbf{9 0 \%}$ EPDM, 30\% SiR + 70\% EPDM, 50\% SiR + 50\% EPDM, 70\% SiR $+30 \%$ EPDM, 90\% SiR + $10 \%$ EPDM, $100 \%$ SiR) were tested for different water droplet arrangements, different water conductivities, different droplet volumes as well as different droplet positioning w.r.t. the electrodes. The $50 \% \mathrm{SiR}+\mathbf{5 0} \%$ EPDM mixture proved to be the best mixture regarding the flashover voltage.
\end{abstract}

Keywords-SIR; EPDM; insulators; high voltage; polymeric

\section{INTRODUCTION}

Polymeric outdoor insulators are in use in the past few decades [1]. One of the most popular insulating materials for this application is silicone rubber [2]. Lately, efforts have been undertaken in order to combine mixtures of silicone rubber (SiR) with ethylene propylene diene monomer (EPDM), which is also a good insulating material. $\mathrm{SiR}$ has excellent hydrophobicity [2] and it performs very well in polluted areas, whereas it lacks in mechanical strength. EPDM has high mechanical strength but its resistance to UV radiation is not that good and it seems to loose, as time passes by, its hydrophobicity [3]. An admixture of the two aforementioned materials may be a good way of having a new polymer with improved properties, both electrical and mechanical. Mixtures of the two materials in various proportions have been studied in [4]. Hydrophobic surfaces are characterized by a low surface energy. On hydrophobic surfaces, water forms discrete droplets and, consequently, leakage currents are minimized and the formation of dry zones becomes more difficult [3]. As a result, the probability of flashover is reduced. The main characteristic of hydrophobicity is the contact angle. The lower the surface energy of the insulating surface, the larger the contact angle $\theta$ [5]. Needless to say that, a hydrophobic surface presents a contact angle of more than $90^{\circ}$ whereas a hydrophilic surface has a contact angle of less than $90^{\circ}$.

On polymeric surfaces, the shape of water droplets depends on the surface material, the surface pollution, the surface deterioration, the droplet conductivity, the surface roughness, the charging of the droplet as well as the angle of the insulator sheds [6]. It has been reported elsewhere that the larger the droplet volume, the smaller the contact angle becomes, and consequently, the probability of a flashover increases [6]. The electric field distribution is greatly affected by the presence of a droplet on an insulating surface. It is already noted that the field lines inside the droplet are less dense because of the high dielectric constant of water. An intensification of electric field is observed at the triple junctions (where the three materials, air/droplet/silicone rubber, meet) [6, 7].

When a uniform electric field is applied, a water droplet (not charged) begins to oscillate at a certain field value. The oscillation frequency may be twice as much of that of the applied voltage. As the voltage increases, the oscillation becomes even more pronounced until a flashover ensues. With a charged droplet, the shape of the droplet -as the voltage increase- becomes asymmetrical and the oscillation frequency is the same with that of the applied voltage [6]. In the context of the present paper, various mixtures of SiR/EPDM $(100 \%$ EPDM, $10 \% \mathrm{SiR}+90 \% \mathrm{EPDM}, 30 \% \mathrm{SiR}+70 \% \mathrm{EPDM}, 50 \%$ $\mathrm{SiR}+50 \% \mathrm{EPDM}, 70 \% \mathrm{SiR}+30 \% \mathrm{EPDM}, 90 \% \mathrm{SiR}+10 \%$ EPDM, 100\% SiR) were investigated, with the purpose to see which of them presented the highest flashover voltage. In order to observe this, a uniform electrode arrangement was used. Since the flashover voltage is affected by the presence of humidity (water droplets) on the surface of an insulator, water droplets of various conductivities and volumes were placed on the surface of the samples.

\section{SIR/EPDM MIXTURES}

Silicone rubber is widely used for outdoor insulation because of its excellent hydrophobicity, good resistance to oxidation and ozone as well its perseverance in higher temperatures. Moreover, it is thermally stable and it functions well under polluted conditions. It is, however, more expensive than other insulating materials and it has a smaller mechanical strength. EPDM performs well under high temperatures and humidity, it presents small dielectric losses and very good dielectric strength, it is resistant to corona discharges and it is 
less expensive compared to silicone rubber. It is, however, sensitive to UV radiation and to pollution and it is less thermally stable in comparison to SiR. It is intended that a combination of the two aforementioned materials may give improvements regarding the mechanical strength, the resistance to UV radiation and to oxidation and ozone, the thermal stability, the hydrophobicity and the cost $[6,8,9]$. It has been observed that, generally speaking, the electrical properties improve with the increase of $\mathrm{SiR}$ in the mixture. Regarding the mechanical properties, the tensile strength decreases with the percentage increase of $\mathrm{SiR}$, in other words, a percentage increase of SiR implies a reduction of mechanical strength.

Data published elsewhere, regarding the relation between the various percentages of SiR/EPDM mixtures with important quantities, such as tracking resistance, tensile strength, dielectric strength, surface resistivity, volume resistivity, arc resistance and dielectric constant, indicated that there is an interplay between the percentages of the two materials w.r.t. the above properties [4]. Referring to the experimental data of [4], it is understandable that the mechanical strength of SiR can be considerably increased with the addition of EPDM. A $\mathrm{SiR} / \mathrm{EPDM}$ mixture renders somehow worse electrical properties - in comparison to a $100 \% \mathrm{SiR}$ - but such a decrease is not that big when the addition of EPDM is not more than $50 \%$. Mixtures having equal quantities of SiR and of EPDM present good electrical and mechanical properties. An addition of more than 50\% EPDM is not to be recommended because of a significant degradation of the electrical properties. Mixtures with more than $70 \%$ SiR present excellent electrical properties but their mechanical strength is not that satisfying. Furthermore, mixtures of $50 \% \mathrm{SiR}+50 \%$ EPDM are less expensive than "pure" SiR.

\section{EXPERIMENTAL EQUIPMENT}

For the experiments, a dry transformer was used giving voltages up to $24 \mathrm{kV}$. A horizontal wooden surface was used for putting the samples. Two copper electrodes were used. In the photographs shown in Figure 1 the power supply, the electrodes and the horizontal wooden surface, on which the experiments were performed, can be seen. The insulating materials used in the context of the present paper are given in Table I.

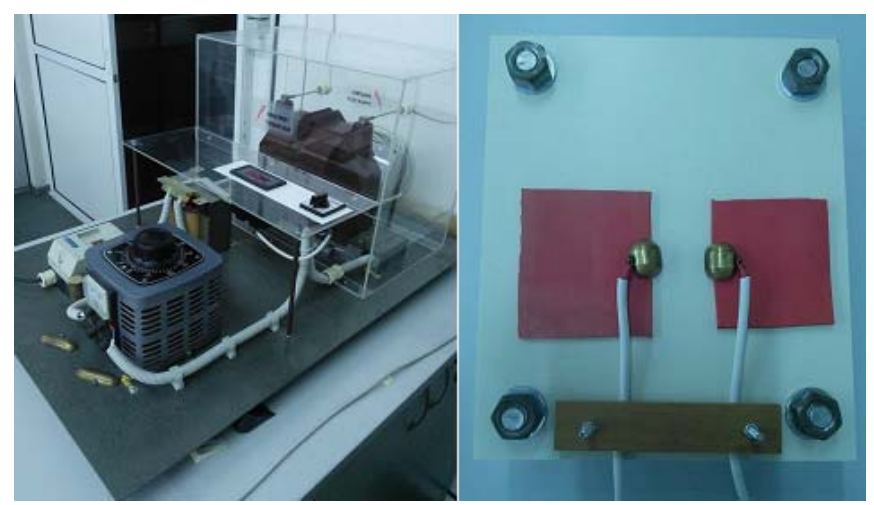

Fig. 1. Experimental set-up
TABLE I. MIXTURE COMPOSITION

\begin{tabular}{|c|c|c|}
\hline Blend & Percentage in SiR & Percentage in EPDM \\
\hline $\mathrm{A}$ & $90 \%$ & $10 \%$ \\
\hline $\mathrm{B}$ & $70 \%$ & $30 \%$ \\
\hline $\mathrm{C}$ & $50 \%$ & $50 \%$ \\
\hline $\mathrm{D}$ & $30 \%$ & $70 \%$ \\
\hline $\mathrm{E}$ & $10 \%$ & $90 \%$ \\
\hline
\end{tabular}

IV. CONDUCTIVITIES, DROPLET ARRANGEMENTS AND EXPERIMENTAL PROCEDURE

Water droplets of various conductivities were used, from almost distilled water $(1.4 \mu \mathrm{S} / \mathrm{cm})$ up to $10000 \mu \mathrm{S} / \mathrm{cm}$ (conductivities used were: $1.4 \mu \mathrm{S} / \mathrm{cm}, 100 \mu \mathrm{S} / \mathrm{cm}, 200 \mu \mathrm{S} / \mathrm{cm}$, $500 \mu \mathrm{S} / \mathrm{cm}, 1000 \mu \mathrm{S} / \mathrm{cm}, 2000 \mu \mathrm{S} / \mathrm{cm}, 5000 \mu \mathrm{S} / \mathrm{cm}$ and 10000 $\mu \mathrm{S} / \mathrm{cm})$. The droplets arrangements are shown in Figure 2. In the top arrangement (with one droplet) has a volume of $0.1 \mathrm{ml}$, at a distance of $1.25 \mathrm{~cm}$ from the electrodes. In the bottom arrangement, the two droplets have each volume of $0.05 \mathrm{ml}$, and their distance from the respective electrodes is $0.8 \mathrm{~cm}$. The electrodes in all experiments were at a distance of $2.5 \mathrm{~cm}$ from each other.

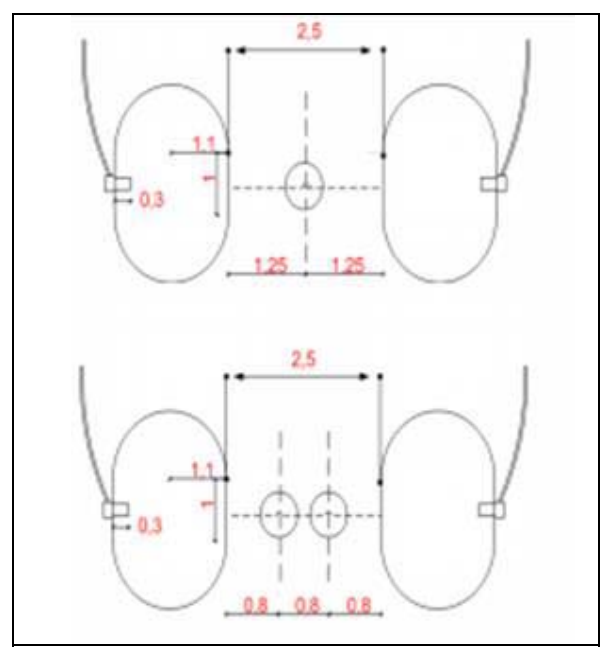

Fig. 2. Water droplet arrangements

After positioning the droplets on the polymer surface, the voltage was slowly raised until flashover occurred. After that and after cleaning the surface and positioning new droplets on it, the voltage was raised up to the previous flashover value minus $1.2 \mathrm{kV}$, so that no new flashover would occur. At this voltage value, the arrangements could stay for $5 \mathrm{~min}$. If no flashover occurred, the voltage was raised by $0.4 \mathrm{kV}$ and the procedure was repeated until flashover occurred. The new flashover value was recorded. The reason for allowing the voltage for $5 \mathrm{~min}$ at each voltage level was because a ceratin time was required for the droplets to deform and for the PD to start. The deformation of a single droplet can be seen in Figure 3. In Figure 4, the successive phases of formation of an arc are given for a single droplet of $1000 \mu \mathrm{S} / \mathrm{cm}$ on sample $\mathrm{C}$.

The oscillations of droplets on samples rich in $\mathrm{SiR}$ (mixtures A and B) are more intense because of their better hydrophobicity, i.e. for a constant droplet volume, in hydrophobic materials, the contact angle is large and the 
contact surface small and, consequently, the droplet oscillates more. The flashovers on samples rich in $\mathrm{SiR}$ are more intense, thus forming bigger arcs. An increase in droplet volume, in droplet number as well as in water conductivity, leads to a flashover in lower voltages. Increase of conductivity, and especially at values of $5000 \mu \mathrm{S} / \mathrm{cm}$ and $10000 \mu \mathrm{S} / \mathrm{cm}$, causes deterioration of the sample surface. Samples rich in EPDM show more intensive deterioration (especially in the higher water conductivities), as is shown in Figure 5. Rich in EPDM samples showed a reduction of flashover voltage because of the deterioration of their surface.

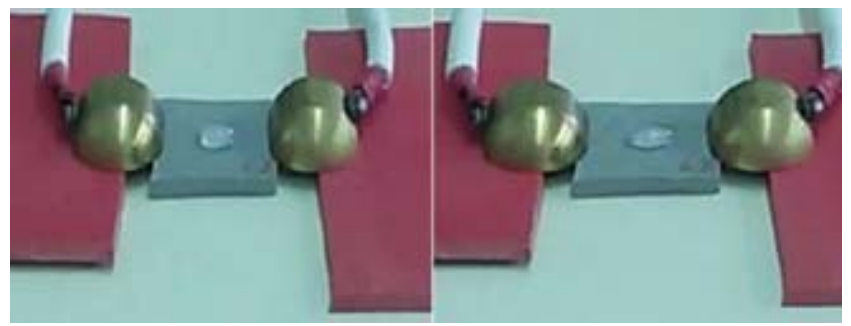

Fig. 3. Deformation of a single droplet on sample A (droplet conductivity $1.4 \mu \mathrm{S} / \mathrm{cm})$

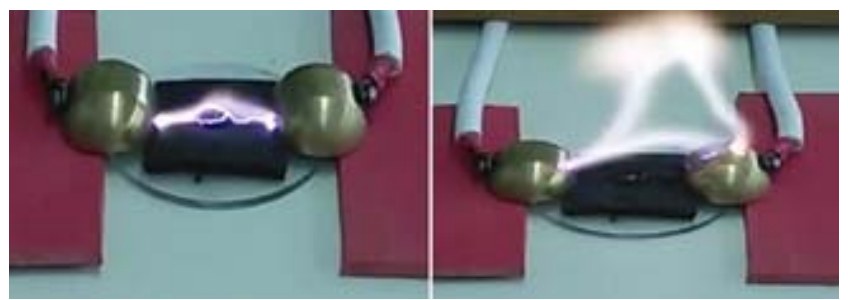

Fig. 4. Arcing of a single droplet on sample C

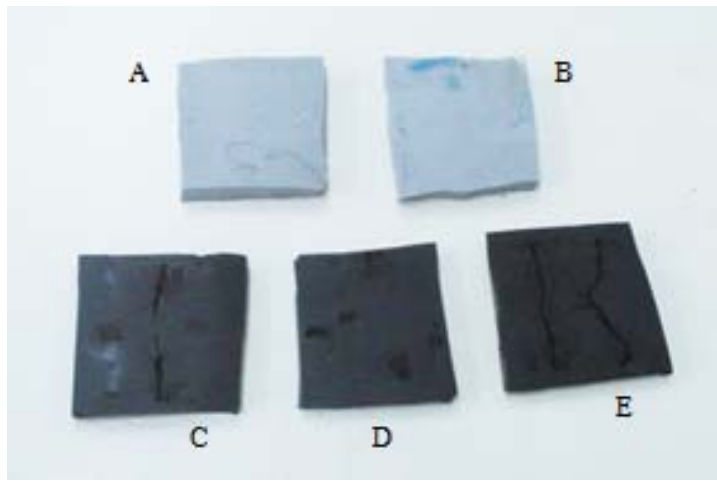

Fig. 5. The state of the samples after the experiments.

\section{EXPERIMENTAL RESULTS AND DISCUSSION}

Figure 6 refers to flashover voltages for samples A, B, C, $\mathrm{D}$, and $\mathrm{E}$ (Table I) and for a droplet volume of $0.1 \mathrm{ml}$ at a distance of $1.25 \mathrm{~cm}$ from the electrodes. Figure 7 shows flashover voltages for samples A, B, C, D, and E for an arrangement of two droplets, each of $0.05 \mathrm{ml}$ at a distance of $0.8 \mathrm{~cm}$ from the electrodes and also between them. From the above mentioned figures, it is evident that the influence of water conductivity on flashover voltage is prominent. No matter the droplet arrangement, the droplet volume or the droplet number, or even the sample composition, an increase in water conductivity leads to a decrease of flashover voltage. Droplet volume as well as droplet number effect was noted previously [10-13]. Larger droplet volume and/or droplet number leads to a lower flashover voltage [14-15. The beneficial effect of silicone rubber on EPDM was also noted recently [16].

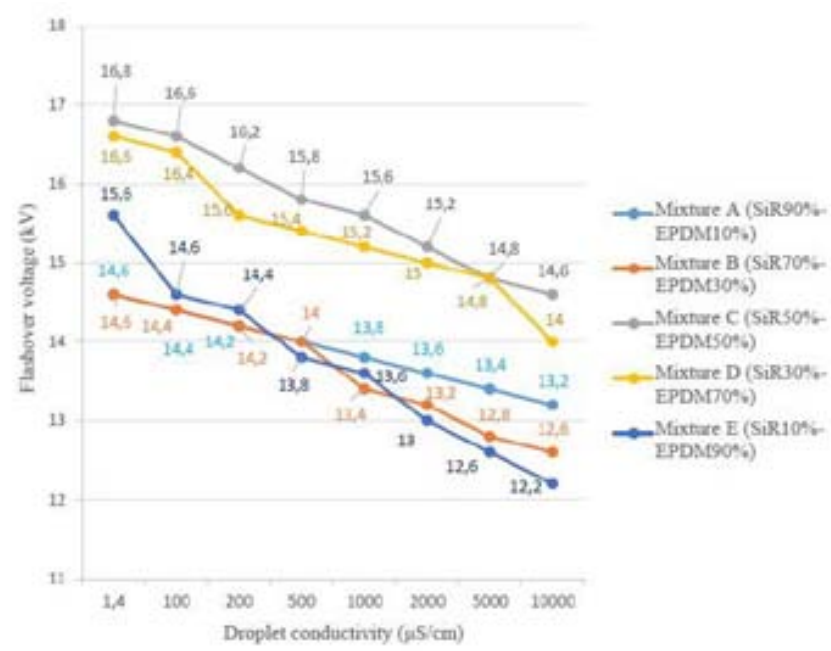

Fig. 6. Flashover voltage in terms of droplet conductivity with a $0.1 \mathrm{ml}$ water droplet for the various mixtures

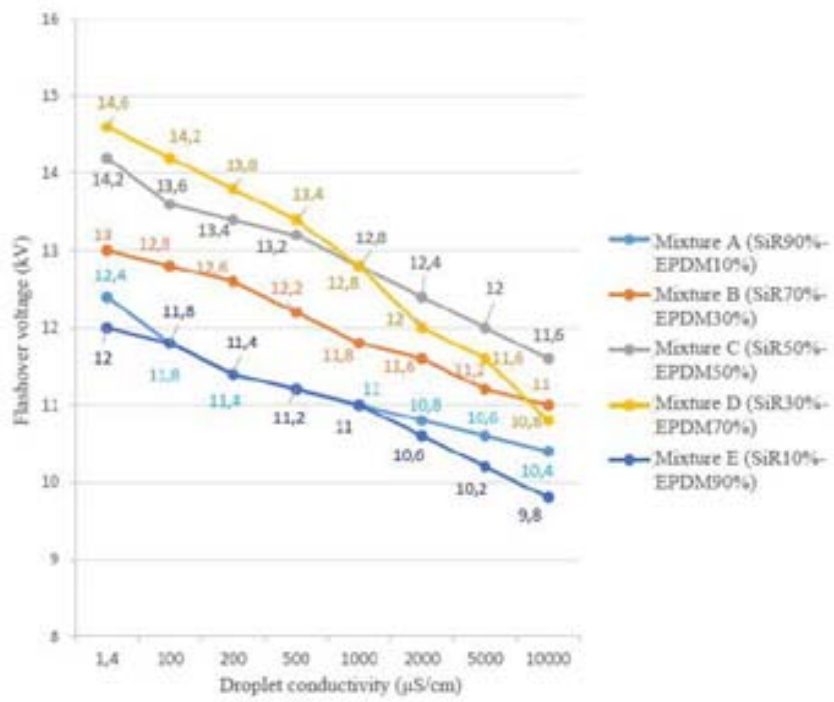

Fig. 7. Flashover voltage in terms of droplet conductivity with two droplets each of $0.05 \mathrm{ml}$ for the various mixtures

It seems that mixture $\mathrm{C}(50 \% \mathrm{SiR}-50 \% \mathrm{EPDM})$ presents a satisfying flashover behavior. This is in accordance with [4], where it was shown that this mixture presented the best combination of electrical and mechanical properties. Mixtures $\mathrm{D}$ and $\mathrm{B}$ (Table 1) follow regarding the flashover behavior. Mixtures A (90\% SiR - 10\% EPDM) and E (10\% SiR - 90\% EPDM) present the worst behavior regarding the flashover 
voltage. From the measurements performed in the context of this work, mixture $\mathrm{C}$ seems to electrically behave the best in comparison with the rest of the mixtures. This is perhaps due to the fact that the percentage $50 \% \mathrm{SiR}-50 \%$ EPDM preserves somehow in the best way the electric and mechanical properties of the constituent materials.

For future work, it is recommended a further series of experiments regarding surface discharges and flashover voltages, taking into account the surface roughness of the samples, the more detailed study of the contact angle for the various blends as well as the use of other electrode arrangements and larger samples. The latter will allow the probable use of larger water droplets, which in turn will give a more ample variety of results.

\section{CONCLUSION}

In the context of this paper, an investigation was performed for various mixtures of SiR and EPDM, regarding the flashover voltage. Experiments with water droplets of various conductivities under the influence of a uniform electric field indicated that the mixture having $50 \% \mathrm{SiR}-50 \% \mathrm{EPDM}$ gives the most satisfactory data. This renders the aforementioned mixture a reliable candidate for industrial outdoor high voltage applications.

\section{ACKNOWLEDGMENTS}

The samples were prepared at SSN College of Engineering, Department of Electrical and Electronics Engineering, Chennai, Tamil Nadu, India.

\section{REFERENCES}

[1] R. Gorur, "High voltage outdoor insulation technology", Cont. a. Dyn. Syst., Vol. 44, pp. 131-191, 1994

[2] M. G. Danikas, "Ageing properties of silicone rubber materials used in high voltage composite insulators", J. Elec. Electron. Engg., Austr., Vol.15, No. 2, pp. 193-202, 1995

[3] S. M. Gubanski, A. E. Vlastos, "Wettability of naturally aged silicone and EPDM composite insulators", IEEE Transactions on Power Delivery, Vol. 5,No. 3, pp. 1527 - 1535, 1990

[4] R. R. Prabu, S. Usa, K. Udayakumar, M. A. Khan, S. S. M. Abdul Majeed, "Electrical insulation characteristics of silicone and EPDM polymeric blends - Part I", IEEE Trans. Diel. Electr. Insul., Vol. 14, No. 5, pp. 1207-1214, 2007

[5] J. K. Kim, In-Hwan Kim, "Characteristics of surface wettability and hydrophobicity and recovery ability of EPDM rubber and silicone rubber for polymer insulators", J. Appl. Polymer Sci., Vol. 79, pp. 2251-2257, 2001

[6] O. Fujii, K. Honsali, Y. Mizuno, K. Naito, "A basic study on the effect of voltage stress on a water droplet on a silicone rubber surface", IEEE Trans. Diel. Electr. Insul., Vol. 16, No. 1, pp. 116-122, 2009

[7] E. Kuffel, W. S. Zaengl, J. Kuffel, High Voltage Engineering: Fundamentals, Eds. Newness, Oxford, UK, 2000

[8] M. Mohseni, M. Geramian, H. Mirzadeh, "Manufacturing and evaluation of EPDM-silicone blends used in housing of high voltage composite insulators", Proc. 17th Int. Conf. Electricity Distribution, Paper No. 44 Session 1, Barcelona, Spain, 2003

[9] R. Deepalaxmi, V. Rajini, "Performance evaluation of gamma irradiated SiR-EPDM blends", Nuclear Engineering and Design, Vol. 273, pp. $602-614,2014$
[10] A. Bairaktari, M. Danikas, X. Zhao, Y. Cheng, Y. Zhang, "Behaviour of Water Droplets Under the Influence of a Uniform Electric Field in Nanocomposite Samples of Epoxy Resin/TiO2”, Engineering, Technology \& Applied Science Research, Vol. 3, No. 5, pp. 511-515, 2015

[11] C. Charalambous, M. Danikas, Y. Yin, N. Vordos, J. W. Nolan, A. Mitropoulos, "Study of the Behavior of Water Droplets Under the Influence of a Uniform Electric Field on Conventional Polyethylene and on Crosslinked Polyethylene (XLPE) with MgO Nanoparticles Samples”, Engineering, Technology \& Applied Science Research, Vol. 7, No. 1, pp. 1323-1328, 2017

[12] M. G. Danikas, P. Rakitzis, K. Karakoulidis, "Study of parameters related to deterioration phenomena due to water droplets on polymeric surfaces”, J. Electr. Eng., Vol. 57, No. 3, pp. 130-137, 2006

[13] M. G. Danikas, P. Ramnalis, R. Sarathi, "Experimental results on the behavior of water droplets on polymeric surfaces under the influence of electric fields: The case of an inclined test arrangement for PVC, rubber and silicone rubber", Funktechnikplus Journal, Vol. 1, No.2, pp. 19-39, 2013

[14] K. Karakoulidis, M. G. Danikas, P. Rakitzis, "Deterioration phenomena on polymeric insulating surfaces due to water droplets", J. Electr. Eng., Vol. 56, No. 7-8, pp. 169-175, 2005

[15] S. C. Kechagia, M. G. Danikas, R. Sarathi, "Water droplets and breakdown phenomena on polymer nanocomposite surfaces under the influence of uniform electric fields", Malaysian Polym. J., Vol. 8, No. 2, pp. 41-47, 2013

[16] A. Ragab, L. S. Nasrat, S. M. El-Khodary, S. El-Debeiky, "Performance of EPDM cable terminations under various polluted conditions", International Journal of Innovative Research in Electrical, Electronics, Instrumentation and Control Engineering, Vol. 2, No. 8, pp. 1780-1783, 2014 